Eutectogels: A New Class of Solid Composite Electrolytes for Li/Li-Ion Batteries Peer-reviewed author version

JOOS, Bjorn; VRANKEN, Thomas; MARCHAL, Wouter; SAFARI, Momo; VAN

BAEL, Marlies \& HARDY, An (2018) Eutectogels: A New Class of Solid Composite

Electrolytes for Li/Li-Ion Batteries. In: CHEMISTRY OF MATERIALS, 30 (3), p. 655-662.

DOI: 10.1021/acs.chemmater.7b03736

Handle: http://hdl.handle.net/1942/25696 


\title{
Eutectogels: a New Class of Solid Composite Electrolytes for Li/Li- ion Batteries
}

\author{
Bjorn Joos*, Thomas Vranken, Wouter Marchal, Mohammadhosein Safari, Marlies K. Van Bael, \\ An T. Hardy
}

AUTHOR ADDRESS UHasselt, Hasselt University, Institute for Materials Research (IMO), and imec division imomec, Agoralaan, 3590 Diepenbeek, Belgium

KEYWORDS deep eutectic solvents, composite solid electrolytes, lithium ion batteries, ionic liquids, silica matrix

\begin{abstract}
Here, we introduce deep eutectic solvent (DES) - silica composites as a promising candidate for solid composite electrolytes (SCEs). The proposed DES-based gel electrolytes, further referred to as eutectogels (ETGs), are characterized by high ionic conductivity $\left(1.46 \mathrm{mS} \mathrm{cm}^{-1}\right.$ ), thermal (up to $130{ }^{\circ} \mathrm{C}$ ), and electrochemical stability (up to 4.8 volts) and are chemically inert to solvents and water. These ETGs can be easily processed and potentially at lower costs compared to ionicliquid-based composite electrolytes. The good prospects of ETGs for application in $\mathrm{Li} / \mathrm{Li}$-ion batteries are demonstrated by stable cycling of $\mathrm{Li} / \mathrm{ETG} / \mathrm{LiFePO}_{4}$ cells over 100 cycles at $\mathrm{C} / 10$.
\end{abstract}

\section{INTRODUCTION}

The thirst for better rechargeable batteries parallels the recent rise in the public's and governments' awareness of climate change and global warming. Such batteries are essential in order to realize the electrification of road transport and residential storage of renewable energies. For these applications, a gradual move beyond the stateof-the-art Lithium-ion batteries (LIBs) is inevitable on account of their potential safety hazards, high price, and gravimetric/volumetric storage limits. These shortcomings are believed to be resolved to a great extent by the development of an ideal solid electrolyte. ${ }^{\text {T The organic liquid }}$ electrolytes in conventional LIBs are flammable, prone to excessive oxidation at potentials as low as $4.2 \mathrm{~V}$ vs. Li, and unable to stop the growth of lithium dendrites. ${ }^{2-4}$ Hence, a Li-ion conductive solid electrolyte with a broader electrochemical and thermal stability is highly desired in order to enable the deployment of next generation of insertion cathodes, e.g., high voltage LMNO, and to revive the ancestor of LIBs, i.e., Li-metal batteries (LMBs).

In recent years, the concept of solid composite electrolyte (SCE) has aroused considerable interest in the battery

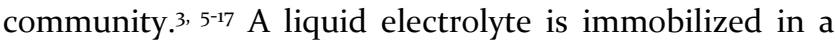
solid skeleton resulting in a SCE which is then endowed with the synergies from both components. Ionogels are good examples of SCEs in which an ionic liquid is confined within an inorganic (e.g., Silica), or hybrid (e.g., SilicaPVDF-co-HEA) solid matrix.3, 5-17 A new class of solvents have emerged recently, i.e. the deep eutectic solvents
(DES). ${ }^{18-21}$ These solvents share many attributes with the ionic liquids among which a low vapor pressure and nonflammability. However, they benefit from additional advantages such as ease of fabrication and low cost of components. ${ }^{19},{ }^{21-24}$ An ionic liquid is a pure substance composed of a discrete cation and anion, the bulkiness of these ions lowers the melting point of the salt well below room temperature. ${ }^{21,} 25$ On the other hand, a DES consists of an eutectic mixture of two or more substances. In contrary to the ionic liquids, DES systems are formed by complexation of ions with Lewis and/or Brönsted acids and bases. ${ }^{21}$ The complexation reaction results in large non-symmetrical ions, which lower the lattice energy and hence the melting points. Boisset et al. extensively investigated DES systems composed of lithium Bis(trifluoromethane)sulfonimide lithium salt (LiTFSI) and acetamide for application in Liion batteries and capacitors. ${ }^{26-28}$

Here, we introduce eutectogels (ETGs) as a new class of SCEs in which a DES is confined within a silica matrix. ETGs are prepared over a broad range of compositions via a non-aqueous sol-gel route and further characterized by FT-IR and TGA/DSC/MS methods in order to measure their chemical and thermal stabilities, respectively. The ionic conductivity and electrochemical stability window of ETGs are further determined by means of electrochemical impedance spectroscopy (EIS) and Voltammetry experiments. Finally, the as prepared ETGs are galvanostatically cycled in $\mathrm{Li}|\mathrm{ETG}| \mathrm{LiFePO}_{4}$ coin cells and their prospects for applications in LIBs and LMBs are discussed. 


\section{EXPERIMENTAL}

Materials

Formic acid (FA, puriss. p.a., ACS reagent, reag. Ph. Eur., $\geq 98 \%$ ), bis(trifluoromethane)sulfonimide lithium salt (LiTFSI, 99.59\% trace metals basis), tetraethylorthosilicate (TEOS, reagent grade, 98\%), and n-methylacetamide (NMAC, $\geq 99 \%$ ) were purchased from Sigma Aldrich. All reagents were used as received.

\section{Preparation of ETG nanocomposite electrolytes}

The deep eutectic solvent was synthesized according to the procedure by Boisset et al. ${ }^{26-28}$ LiTFSI and NMAC were added together in a 1:4 molar ratio, and stirred vigorously for 3 hours in a nitrogen-filled glove box $\left(\mathrm{H}_{2} \mathrm{O}<0.1 \mathrm{ppm}\right.$, $\mathrm{O}_{2}<0.1 \mathrm{ppm}$ ), until a transparent liquid was obtained. The ETGs were prepared using a non-aqueous sol-gel route, as is common knowledge in literature. ${ }^{7,9,14}$ First, TEOS was added to formic acid (molar ratio TEOS:FA = 1:8.7) and vigorously stirred until a homogeneous solution was obtained. Subsequently, the desired amount of silica precursor was added to the deep eutectic solvent and stirred for 5 minutes until a homogeneous, transparent, colorless solution was obtained. Five different ETGs were prepared with different loading of DES inside the silica framework (Table 1), keeping the respective molar ratios of NMAC/LiTFSI and TEOS/FA constant. The solution was cast into PDMS moulds, serving as templates for circular membranes, in ambient air, and cured overnight at room temperature in ambient air until gelation was complete. Next, the ETGs were dried at $45^{\circ} \mathrm{C}$ on a hot plate in ambient air for $72 \mathrm{~h}$ in order to remove the excess of formic acid and side products. Subsequently, the electrolytes were dried at $80{ }^{\circ} \mathrm{C}$ under high vacuum (Büchi glass oven B-585) for 16 hours and transferred into an argon-filled glove box $\left(\mathrm{H}_{2} \mathrm{O}<0.1 \mathrm{ppm}, \mathrm{O}_{2}<0.6 \mathrm{ppm}\right.$, Sylatech). ETG membranes with a thickness of maximum $2.4 \mathrm{~mm}$ were obtained.

Preparation of the Li | ETG | LFP cells

The $\mathrm{LiFePO}_{4}$ (LFP) electrodes were fabricated from a slurry of $\mathrm{LiFePO}_{4}$ (MTI corporation), carbon black (Super C65, Imerys) and PVDF (Alfa Aesar) in n-methyl-2-pyrrolidone (Alfa Aesar, 99.0\%+) with a weight ratio of 80:10:10. The well-mixed slurry was tape casted on $\mathrm{Al}$ foil and further dried at $110{ }^{\circ} \mathrm{C}$ for $16 \mathrm{~h}$ in order to obtain electrodes with an approximate thickness of $6.5 \mu \mathrm{m}$ and an active-material loading of $0.9 \mathrm{mg} \mathrm{cm}^{-2}$. The Li/ETG/LFP coin cells (LR2025) were assembled in an argon-filled glovebox by placing LFP electrode in front of a Li foil separated by ETG in between. The cells were left at rest for 24 hours.

\section{Characterization}

\section{(Physico-)chemical characterization}

The morphology of the ETGs was characterized by scanning electron microscopy (SEM, FEI Quanta 20o FEG-SEM equipped with secondary and back-scattered electron detectors). Additionally the DES was extracted from the ETGs with milliQ water by sonication (30 minutes) and centrifugation ( 15 minutes, $14.000 \mathrm{~g}$ ) for three times. The obtained precipitate was dried and characterized with transmission electron microscopy (FEI Technai G2 Spirit Twin electron microscope, operated at $120 \mathrm{kV}$ ) and nitrogen physisorption with an Autosorb IQ station 1 to elucidate the nanostructure of the silica framework. The water content of the ETGs was evaluated by coulometric Karl-Fisher titration (Metrohm Titrando). Thermogravimetric analysis (Q500 TA instruments) coupled with mass spectrometry (Q50oo TA instruments, Pfeiffer quadrupole MS, High-T Pt sample pan) of the ETGs was carried out from room temperature to $600{ }^{\circ} \mathrm{C}$ at $10^{\circ} \mathrm{C} \mathrm{min}^{-1}$ under a nitrogen atmosphere $\left(60 \mathrm{ml} \mathrm{min}^{-1}\right)$. The TGA chamber was flushed with nitrogen gas for 20 minutes before starting the measurement. Calorimetric experiments were carried out by a differential scanning calorimeter (DSC, TA Instruments Q20o) from $-90{ }^{\circ} \mathrm{C}$ to $60{ }^{\circ} \mathrm{C}$ (heating rate $10{ }^{\circ} \mathrm{C} \mathrm{min}^{-1}$ ). The ETGs were enclosed in an aluminium pan and cycled under a nitrogen flow of $50 \mathrm{ml} \mathrm{min}{ }^{-1}$. The DSC chamber was flushed with nitrogen gas for 20 minutes before starting the measurement. The viscosity of the DES was analyzed with a TA instruments ARG2 Rheometer, cone geometry, $25{ }^{\circ} \mathrm{C}$ peltier plate, shear rates ranging from 1 to $1000 \mathrm{~s}^{-1}$. The composition of the ETGs was determined with inductively coupled plasma atomic emission spectroscopy (ICPAES, Perkin Elmer Optima 830o) and the Kjeldahl method. The latter was used to determine the nitrogen content of the ETG. For the determination of lithium and sulphur, the DES was extracted from the ETGs with milliQ water by sonication (30 minutes) and centrifugation (15 minutes, $14.000 \mathrm{~g}$ ) for three times. Subsequently, the obtained extract was analyzed with ICP-AES. The ETGs, silica and standalone DES were dispersed in a $\mathrm{KBr}$ pellet (o.4 mass\%) and analyzed by means of FTIR (Bruker Vertex 70, 32 scans, scan range $4000-400 \mathrm{~cm}^{-1}$, resolution $4 \mathrm{~cm}^{-1}$ ) at room temperature.

\section{Electrochemical characterization}

The ionic conductivity of the ETG electrolytes was measured for a broad range of temperature $\left(-14{ }^{\circ} \mathrm{C}\right.$ to $55^{\circ} \mathrm{C}$ using a VWR AD15R-30 thermostat) by conducting the electrochemical impedance spectroscopy (EIS) tests in a symmetric $\mathrm{Li} / \mathrm{ETG} / \mathrm{Li}$ Swagelok-type cell. EIS (Autolab

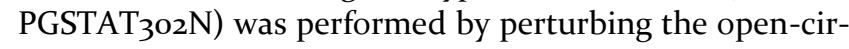
cuit potential with an $\mathrm{AC}$ sinusoidal potential of $10 \mathrm{mV}$ amplitude over a frequency range of $0.1 \mathrm{~Hz}$ to $1 \mathrm{MHz}$. Cyclic voltammetry (CV) and linear sweep voltammetry (LSV) tests (Autolab PGSTAT302N) were carried out in order to investigate the electrochemical stability of ETG membranes at room temperature. To do so, ETG membranes were placed in a coin cell between stainless steel (working electrode) and lithium (reference/counter electrode) and further the potential was swept between $-1 \mathrm{~V}$ and $5 \mathrm{~V}$ vs. $\mathrm{Li}^{+} / \mathrm{Li}$ for the $\mathrm{CV}$ while the limits o $\mathrm{V}$ and $5.5 \mathrm{~V} \mathrm{vs.} \mathrm{Li}^{+} / \mathrm{Li}$ were used in the LSV measurements, both at a scan rate of $10 \mathrm{mV} \mathrm{s}^{-1}$. The Li | ETG | LFP cells were galvanostatically cycled at different $\mathrm{C}$-rates for 10 cycles each, namely $\mathrm{C} / 20$, $\mathrm{C} / 10, \mathrm{C} / 5, \mathrm{C} / 2$ and $\mathrm{C} / 1$, between 2.5 and $4.2 \mathrm{~V}$ (Bio-Logic $\mathrm{BCS}-805$ ) to determine the rate-capability. 

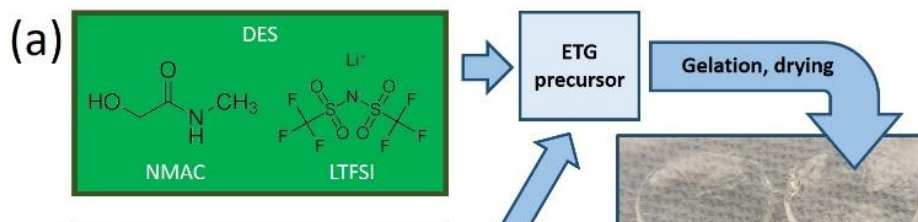

(b)
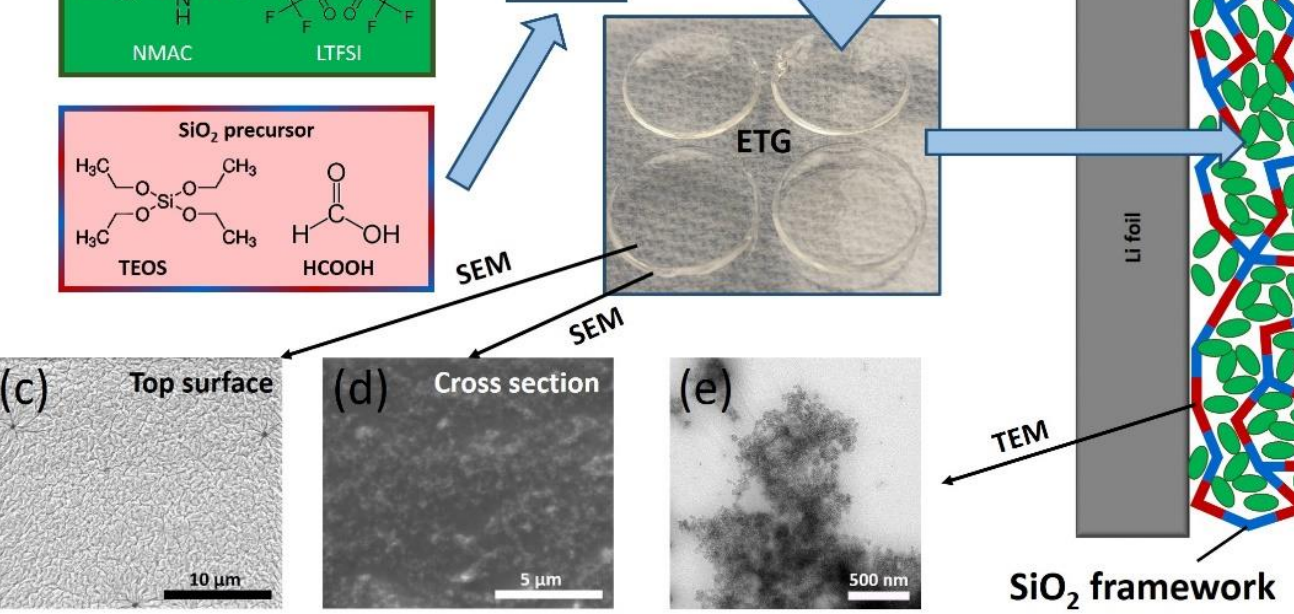

Figure 1: (a) Synthesis route for the ETGs and optical photograph of 4 ETG-5 membranes (12 mm diameter); (b) structural schematic of a Li/LFP cell with the ETG as electrolyte; (c) SEM images of the top surface of a ETG-3 membrane; (d) SEM image of the cross section of a ETG-3 membrane and (e) TEM image of the silica framework (after extraction of the DES).

Long term cycling tests were conducted at a constant $\mathrm{C} / 10$ rate. The $\mathrm{C}$-rate was defined assuming a theoretical capacity of $170 \mathrm{mAh} \mathrm{g}^{-1}$ for LFP electrodes. The rate-capability and cycling tests were repeated on similar Li/ETG/LFP cells assembled with a conventional liquid electrolyte, i.e., $\mathrm{lM} \mathrm{LiPF}_{6}$ in 5o/5o vol\% EC/DEC, for purpose of comparison.

\section{RESULTS AND DISCUSSION}

The $\mathrm{Li}^{+}$-conducting deep eutectic solvent (DES) is a blend of n-methylacetamide and bis(trifluoromethane)sulfonimide lithium salt, further referred to as NMAC and LiTFSI. Recent investigations of DES suggest an optimal molar ratio of LiTFSI:NMAC $=1: 4$ for applications in Li-ion batteries and capacitors. ${ }^{26-28}$ In the present study, the same DES composition is used in order to synthesize the nanocomposite solid electrolytes in which DES is confined within a silica matrix by means of a non-aqueous sol-gel route (figure 1a). Predetermined amounts of DES were mixed with a blend of formic acid (FA) and tetraethyl orthosilicate (TEOS) to obtain 5 hybrid liquid/solid nanocomposite electrolyte with increasing DES loading (ETG$X, X=1$ to 5 , as clarified in Table 1). The FA:TEOS ratio is kept constant at 8.7, similar to other works on ionogels. ${ }^{8,9}$, ${ }^{12}$ The gels were dried under vacuum to remove the formic acid catalyst and silica condensation side-products, i.e. ethanol and water. Karl-Fisher titrations tests confirmed that the water content of the dried gels are below $200 \mathrm{ppm}$.

The obtained ETGs are transparent, homogeneous, glass-like monoliths without cracks (Figure 1a). The thinnest ETGs, with a thickness of about $0.6 \mathrm{~mm}$, were also the thinnest electrolyte membranes used for assembling cells. SEM of the ETGs revealed a uniform cross-linked surface with clear crevices (Figure 1c,d). The cross section of the ETGs clearly showed a porous structure filled with the DES. These morphologies have also been observed in traditional ionogels and are believed to enhance liquid-like $\mathrm{Li}^{+}$mobility within the porous nano-composite. $.5,7,9$

\begin{tabular}{|c|c|c|c|c|c|c|c|}
\hline \multirow[b]{2}{*}{ Sample } & \multicolumn{7}{|c|}{ Sample compositions (in relative molar ratios) } \\
\hline & Formic acid & TEOS & NMAC & LiTFSI & $\begin{array}{l}\text { Mean Pore size } \\
(\mathrm{nm})\end{array}$ & $\begin{array}{l}\mathrm{S}_{\mathrm{BET}} \\
\left(\mathrm{m}^{2} \mathrm{~g}^{-1}\right)\end{array}$ & $\begin{array}{l}\text { Pore volume } \\
\left(\mathrm{cc} \mathrm{g}^{-1}\right)\end{array}$ \\
\hline $\mathrm{SiO}_{2}$ & 8.7 & 1 & o & o & $\mathrm{N} / \mathrm{A}$ & 553 & 0.286 \\
\hline ETG-1 & 8.7 & 1 & 4.8 & 1.2 & 5.7 & 708 & 0.703 \\
\hline ETG-2 & 8.7 & 1 & 6.4 & 1.6 & 6.3 & 650 & 0.788 \\
\hline ETG-3 & 8.7 & 1 & 8.0 & 2.0 & 8.1 & 532 & 0.817 \\
\hline ETG-4 & 8.7 & 1 & 9.6 & 2.4 & 6.6 & 701 & 0.818 \\
\hline ETG-5 & 8.7 & 1 & 11.2 & 2.8 & 8.2 & 661 & 0.978 \\
\hline
\end{tabular}

Table 1: Molar compositions of the ETGs and silica. 


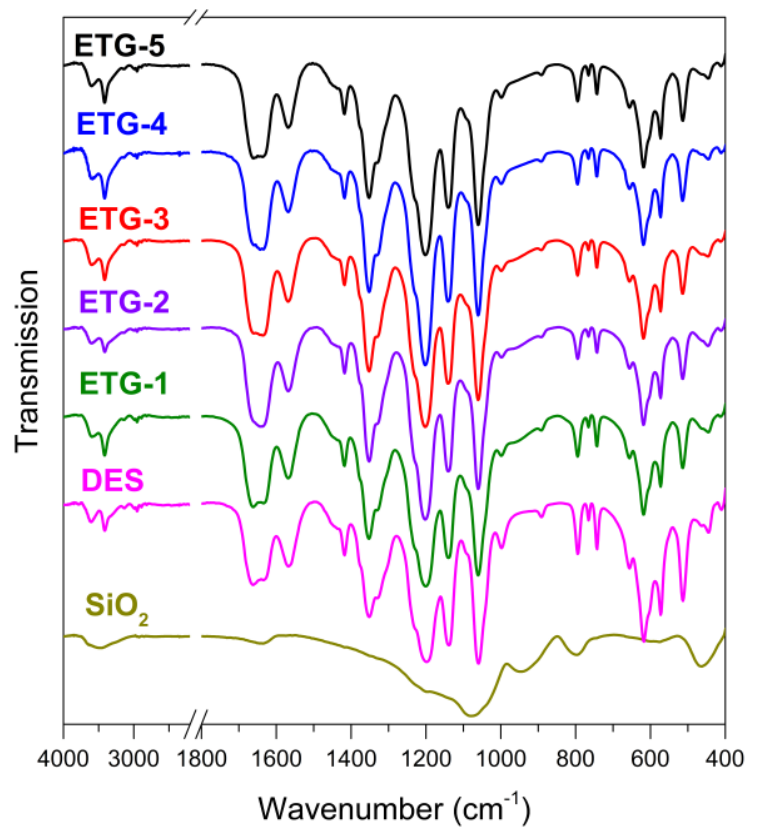

Figure 2: FT-IR spectra of the ETGs, standalone DES and silica framework.

The porous structure of ETGs was further confirmed by nitrogen physisorption of the silica framework after removal of the DES by means of extraction. The isotherms of the ETGs display a type IV(a) shape with $\mathrm{H}_{2}$ hysteresis, indicating the presence of uniform micro and meso-scale pores, see figure S1. The BET and BJH analyses were used to determine the apparent surface areas, between 500 and $710 \mathrm{~m}^{2} \mathrm{~g}^{-1}$, and the pore volumes. The latter shows a clear linear correlation with the loading of the DES inside the ETGs. The lower pore volume of pure silica demonstrates the pore forming role of the DES. The pore size distributions were calculated with the non-localized density functional theory (NLDFT) approach and shown in figure S2. The pore sizes distribution reveals multiple pore size maxima. Hence, the mean pore size in Table 1 is defined as the with diameter with the highest contribution to the pore volume. These results are further supported by the TEM images, showing the formation of cross-linked aggregates from nano-size silica particles, leading to a porous structure (figure 1e).

Ionogels made by a non-aqueous sol-gel route have been widely demonstrated in literature, proving the stability of ionic liquids in acidic media. 5, 9-12, 14, 29 To our best of knowledge, however, there is no report of DES-based ionogel electrolytes in the literature. Hence, we examined the stability of DES against the non-aqueous sol-gel route by means of FT-IR.

\begin{tabular}{lll}
\multicolumn{2}{l}{ Wavenumber $\left(\mathrm{cm}^{-1}\right)$} & Vibration \\
\hline \multicolumn{2}{l}{ DES vibrations } & \\
3410 & 3326 & Amide A \\
3137 & & Amide B \\
2960 & & $v_{\text {as }}\left(\mathrm{CH}_{3}\right)$ \\
2870 & 2820 & $v_{\mathrm{s}}\left(\mathrm{CH}_{3}\right)$ \\
1661 & 1631 & Amide I \\
1565 & & Amide II \\
1452 & 1417 & $\delta_{\mathrm{s}}\left(\mathrm{CH}_{3}\right)$ \\
1353 & & $v_{\text {aip }}\left(\mathrm{SO}_{2}\right)$ \\
1329 & & $v_{\text {aop }}\left(\mathrm{SO}_{2}\right)$ \\
1303 & & $\mathrm{Amide} \mathrm{III}$ \\
1230 & 1190 & $v_{\mathrm{a}}\left(\mathrm{CF}_{3}\right)$ \\
1137 & & $v_{\mathrm{s}}\left(\mathrm{SO}_{2}\right)$ \\
1059 & & $v_{\mathrm{a}}(\mathrm{SNS})$ \\
$\mathrm{SiO}_{2}$ vibrations & \\
1194 & 1072 & $v_{\text {as }}(\mathrm{Si}-\mathrm{O}-\mathrm{Si})$ \\
944 & & $v(\mathrm{Si}-\mathrm{O}-\mathrm{Si})$ \\
797 & & $v_{\mathrm{s}}(\mathrm{Si}-\mathrm{O}-\mathrm{Si})$ \\
570 & & $\mathrm{Si}{ }_{4} \mathrm{O}_{12}$ \\
455 & & $\rho(\mathrm{Si}-\mathrm{O}-\mathrm{Si})$
\end{tabular}

Table 2: Characteristic vibrations of the confined DES and silica framework. ${ }^{30-38}$

The FT-IR spectra of the standalone DES and silica are reported for sake of comparison together with the ETGs (Figure 2), providing us with a clear insight into the chemical structure of ETGs. The FT-IR spectrum of the standalone silica shows the prominent absorption peaks of the two asymmetrical and symmetrical $\mathrm{Si}-\mathrm{O}-\mathrm{Si}$ stretching vibrations at $1194 \mathrm{~cm}^{-1}$ (LO), $1072 \mathrm{~cm}^{-1}$ (TO), and $797 \mathrm{~cm}^{-1}$ respectively. 9, 14, 33, 34, $3^{8}$ The absorption peaks at $455 \mathrm{~cm}^{-1}$, $944 \mathrm{~cm}^{-1}$, and $570 \mathrm{~cm}^{-1} \mathrm{can}$ be attributed to the rocking and stretching vibration of $\mathrm{Si}-\mathrm{O}-\mathrm{Si}$ and vibration originating of the 4-membered siloxane rings $\left(\mathrm{Si}_{4} \mathrm{O}_{12}\right) .39 \mathrm{We}$ argue that the low processing temperature of $80^{\circ} \mathrm{C}$ is insufficient to fully condensate the silica framework whereas in fumed silica or silica glasses the high annealing temperature allows the full condensation. The presence of such absorption bands have been described in literature as well for other low-temperature processed silica particles. ${ }^{39}$ Additionally, the lack of complete silica condensation suggests an open silica framework structure, as observed in the nitrogen physisorption analysis. The absorption bands at $3480 \mathrm{~cm}^{-1}$ and $1640 \mathrm{~cm}^{-1}$ are assigned to the stretching and bending vibration of adsorbed water, respectively. The FT-IR spectra of the standalone DES contain all the prominent bands associated with the NMAC and LiTFSI. The amide A band (composed mainly of the $\mathrm{N}-\mathrm{H}$ stretch vibration) contains primarily the vibration at $3410 \mathrm{~cm}^{-1}$ with a shoulder around $3326 \mathrm{~cm}^{-1}$. The first band can be assigned to the $\mathrm{N}-\mathrm{H}$ stretch 
vibration of the amide with a very weak hydrogen bond with the bulky TFSI- anion..$^{31,32,37}$ The N-H stretch around $3326 \mathrm{~cm}^{-1}$ is red-shifted due to more effective hydrogen bonding with the other amide molecules. The band located at $3600 \mathrm{~cm}^{-1}$ can be attributed to absorbed water in the liquid DES. The bands at $3137 \mathrm{~cm}^{-1}, 2930 \mathrm{~cm}^{-1}, 2870 \mathrm{~cm}^{-1}, 2820$ $\mathrm{cm}^{-1}$ are assigned to the amide $\mathrm{B}$, asymmetric, and symmetric vibrations by the different $\mathrm{CH}_{3}$ moieties. The amide I band of the NMAC component (expected at $1654 \mathrm{~cm}^{-1}$ ) is blue-shifted (to $1661 \mathrm{~cm}^{-1}$ ) in DES and is assigned to tetragonal complexes of the $\mathrm{Li}^{+}$ion with the carbonyl moieties of four NMAC molecules. A second red-shifted amide I band $\left(1631 \mathrm{~cm}^{-1}\right)$ is also present and can be correlated with the much stronger complexation of $\mathrm{Li}^{+}$ions with only one or two NMAC molecules. ${ }^{30-32}$ The characteristic vibrations observed in the FT-IR spectra of ETG are summarized in Table 2. ${ }^{30-36}$ The silica content of the ETGs is limited, i.e. 10 $\mathrm{m} \%$ for the ETG-5 up to $20 \mathrm{~m} \%$ for the ETG-1. Hence the
DES vibrations will dominate. Nonetheless, the FT-IR spectra of the ETGs are found to be a good superposition of the standalone DES and $\mathrm{SiO}_{2}$ spectra. We observe that the absorption bands between $1400 \mathrm{~cm}^{-1}$ and $1000 \mathrm{~cm}^{-1}$ of the ETGs are stronger in intensity compared to those of standalone DES due to the superposition with the strongly absorbing vibrations of the $\mathrm{SiO}_{2}$ framework in this spectral region. The same argument applies for the absorption bands between $3600 \mathrm{~cm}^{-1}$ and $3000 \mathrm{~cm}^{-1}$. Meanwhile the ETGs absorption bands between $700 \mathrm{~cm}^{-1}$ and $500 \mathrm{~cm}^{-1}$ in the fingerprint region are weaker in intensity as strong $\mathrm{SiO}_{2}$ vibrations are absent. New absorption bands are not present in the FT-IR spectra and the vibrations associated with DES remain at the same respective wavenumbers. This suggests that both components of the binary deep eutectic solvent mainly serve as a template for the formation of the silica matrix under acidic conditions.

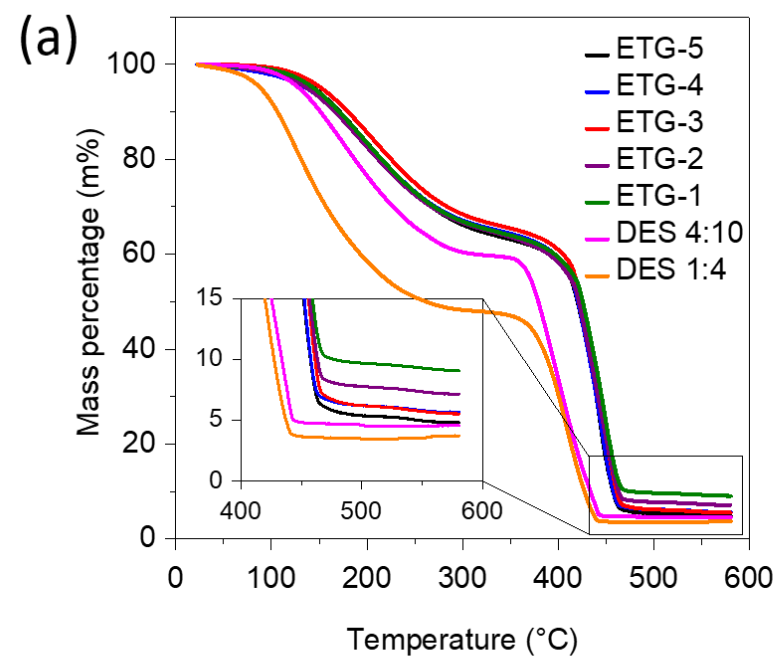

(b)

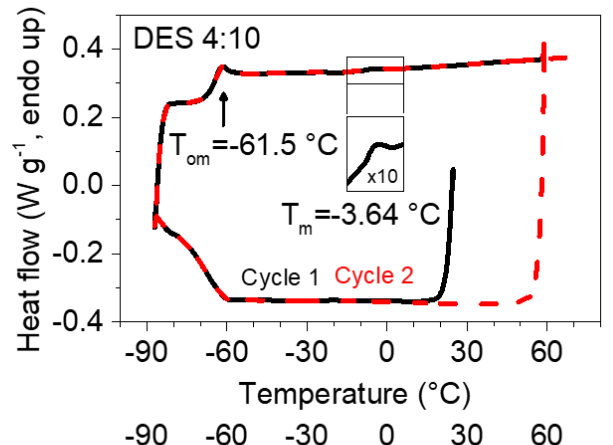

(c)
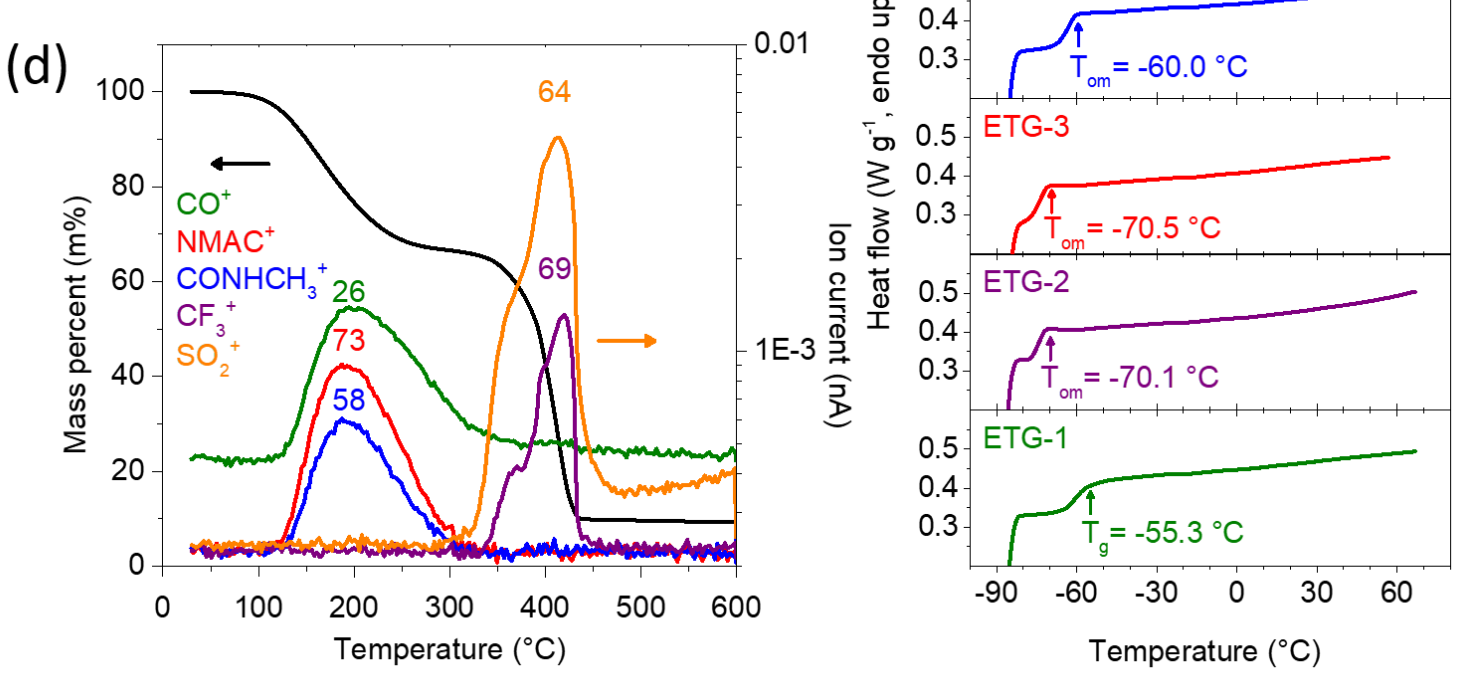

Figure 3: (a) Thermograms and (b), (c) DSC profiles of the reference DES (4:10) and ETGs. (d) Thermogram of ETG-3 with the ion current overlay of selection $\mathrm{m} / \mathrm{z}$ values. The selected $\mathrm{m} / \mathrm{z}$ values: $73,58,26,69,64$ correspond to NMAC, $\mathrm{CONHCH}_{3}$, $\mathrm{CN}, \mathrm{CF}_{3}$ and $\mathrm{SO}_{2}$ respectively. 
Hence, the formic acid catalyst does not react with NMAC component and is removed completely after drying under vacuum supported by TGA-MS experiments (see figure $\mathrm{S}_{3}$ ). Furthermore, strong interaction between the DES and the silanol groups of the silica matrix, e.g. hydrogen bonds, which would have led to broadening of the $\mathrm{N}-\mathrm{H}$ stretching absorptions at around $3410 \mathrm{~cm}^{-1}$ is not observed. This indicates that DES is retained within the pores of the silica framework via physical rather than strong chemical interactions.

The thermal stability of ETGs was studied by thermogravimetric analysis (TGA) and differential scanning calorimetry (DSC). The onset temperature for degradation of ETGs is found to be $131{ }^{\circ} \mathrm{C}$ (Figure 3a) which is lower than that ionogel electrolytes reported in the literature, i.e. onset temperatures $195^{\circ} \mathrm{C}-390^{\circ} \mathrm{C} .9,14 \mathrm{~A}$ two-step mass loss is observed. TGA with on-line MS is used to identify the evolved gasses corresponding to the decomposing or evaporating species corresponding to both mass losses (Figure $3 \mathrm{~d})$. The first gradual mass loss from 131 to $300{ }^{\circ} \mathrm{C}$ corresponds to the evaporation of the NMAC species out of the binary deep eutectic solvent, evident from the $\mathrm{m} / \mathrm{z}$ signals of 73,58 and 26 . The second mass loss with an approximate onset temperature of $413^{\circ} \mathrm{C}$ can be assigned to the thermal degradation of the LiTFSI component. The degradation temperature is well-known in the literature and further confirmed by the $\mathrm{m} / \mathrm{z}$ signals 69 and $64^{44^{-42}}$ These insights clearly prove that low boiling point of NMAC $\left(204{ }^{\circ} \mathrm{C}\right.$ for pure, i.e. no eutectic system) is responsible for the degradation at $131{ }^{\circ} \mathrm{C}$. Hence, further enhancement in thermal stability of ETGs can be realized by using solvents with a higher boiling point. According to thermograms, the molar ratio between LiTFSI and NMAC in ETGs is higher than that of DES, i.e., 0.25. This discrepancy can be attributed to the evaporation of NMAC during the drying step of ETGs prior to TGA analysis. The molar ratio between LiTFSI and NMAC were determined for ETGs following an elemental analysis, ICP-AES, and Kjeldahl-method based on the fluoride and nitrogen content. 43 All samples were found to have a LiTFSI:NMAC molar ratio of $0.40 \pm 0.03$, corresponding to a $50 \%$ loss of NMAC during the drying step. No traces of formic acid or ethanol were found with TGA-MS, confirming their complete removal during the drying steps, see figure $\mathrm{S}_{3}$. A new reference liquid DES was prepared with LiTFSI:NMAC ratio of 4:10 and was used for further analyses in this work. The onset temperatures for the

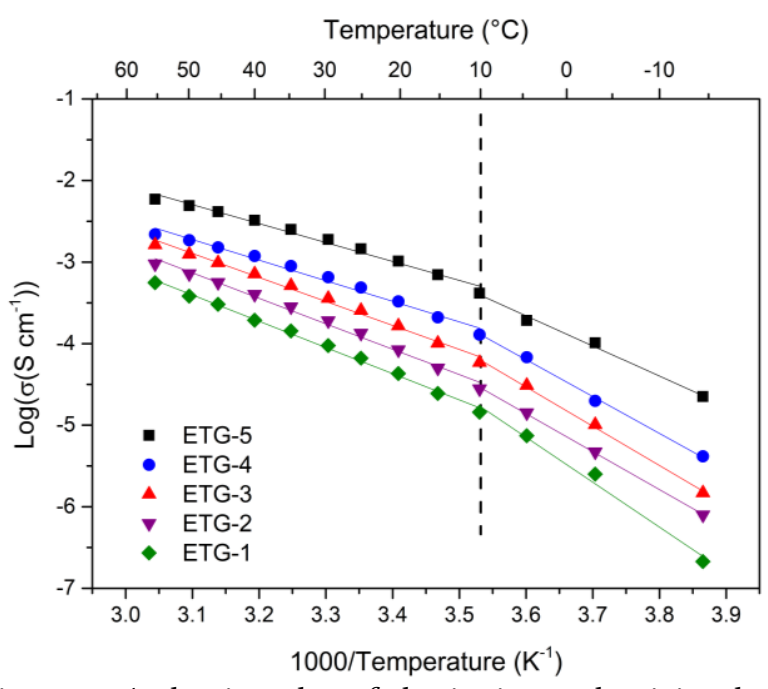

Figure 4: Arrhenius plot of the ionic conductivity determined from symmetric Li/ETG/Li cells.

evaporation and degradation of NMAC and LiTFSI in ETGs, i.e. $131{ }^{\circ} \mathrm{C}$ and $413{ }^{\circ} \mathrm{C}$, respectively, are higher than those of reference pure DES, i.e. $112{ }^{\circ} \mathrm{C}$ and $369^{\circ} \mathrm{C}$. The observed reprieve from evaporation of NMAC and degradation of LiTFSI is a clear evidence for strong confinement of DES within the silica framework. Subsequently, differential scanning calorimetry was used to investigate phase transitions in ETGs. The samples were cooled to $-90{ }^{\circ} \mathrm{C}$ and heated to $60^{\circ} \mathrm{C}$ for two cycles, which both resulted in identical profiles of both cycles and reference DES. The DSC profiles for reference DES and ETGs are shown in figure $3 \mathrm{~b}$, which reveal two melting points. The reference DES shows the onset melting point, correlated with the solidus, at a temperature of $-61.5^{\circ} \mathrm{C}$. The clear melting point, correlated with the liquidus, is found at around $-3.64^{\circ} \mathrm{C}$ for the reference DES. The onset melting point for ETGs falls in a range of $-75{ }^{\circ} \mathrm{C}$ and $-55{ }^{\circ} \mathrm{C}$. No clear trend is visible between the various ETGs with varying DES loads. The clear melting point, however, is only faintly visible in the DSC profile of the ETGs. It can be argued that below $0{ }^{\circ} \mathrm{C}$ solid LiTFSI is present in the ETGs but is completely molten above ${ }^{\circ}{ }^{\circ} \mathrm{C}$. The DSC analysis suggests that DES content of ETGs remains in a liquid state at room temperature which is very beneficial for transport properties of the electrolyte, e.g., ionic conductivity. One of the main challenges that impedes the deployment of solid electrolytes is their rather low ionic conductivities at room temperature.

\begin{tabular}{|c|c|c|c|c|c|c|}
\hline \multirow[t]{2}{*}{ Sample } & \multicolumn{3}{|c|}{$\sigma\left(10^{-3} \mathrm{~S} \mathrm{~cm}^{-1}\right)$} & \multirow{2}{*}{$\begin{array}{c}\mathrm{Ea}>10^{\circ} \mathrm{C} \\
(\mathrm{eV})\end{array}$} & \multirow{2}{*}{$\begin{array}{c}\mathrm{Ea}<10^{\circ} \mathrm{C} \\
(\mathrm{eV})\end{array}$} & \multirow{2}{*}{$\begin{array}{l}\text { Electrochemical window } \\
\quad\left(\mathrm{V} \text { vs. } \mathrm{Li}^{+} / \mathrm{Li}\right)\end{array}$} \\
\hline & $@ 25^{\circ} \mathrm{C}$ & $@ 40^{\circ} \mathrm{C}$ & $@ 55^{\circ} \mathrm{C}$ & & & \\
\hline ETG-1 & 0.07 & 0.19 & 0.56 & 0.64 & 1.10 & $1.1-4.9$ \\
\hline ETG-2 & 0.13 & 0.40 & 0.95 & 0.62 & 0.92 & $1.1-4.8$ \\
\hline ETG-3 & 0.26 & 0.72 & 1.63 & 0.58 & 0.95 & $1.1-4.7$ \\
\hline ETG-4 & 0.49 & 1.19 & 2.19 & 0.51 & 0.90 & $1.1-4 \cdot 7$ \\
\hline ETG-5 & 1.46 & 3.25 & 5.90 & 0.46 & 0.73 & $1.1-4.7$ \\
\hline
\end{tabular}

Table 3: The ionic conductivities, activation energy and electrochemical stability window of the ETGs. 

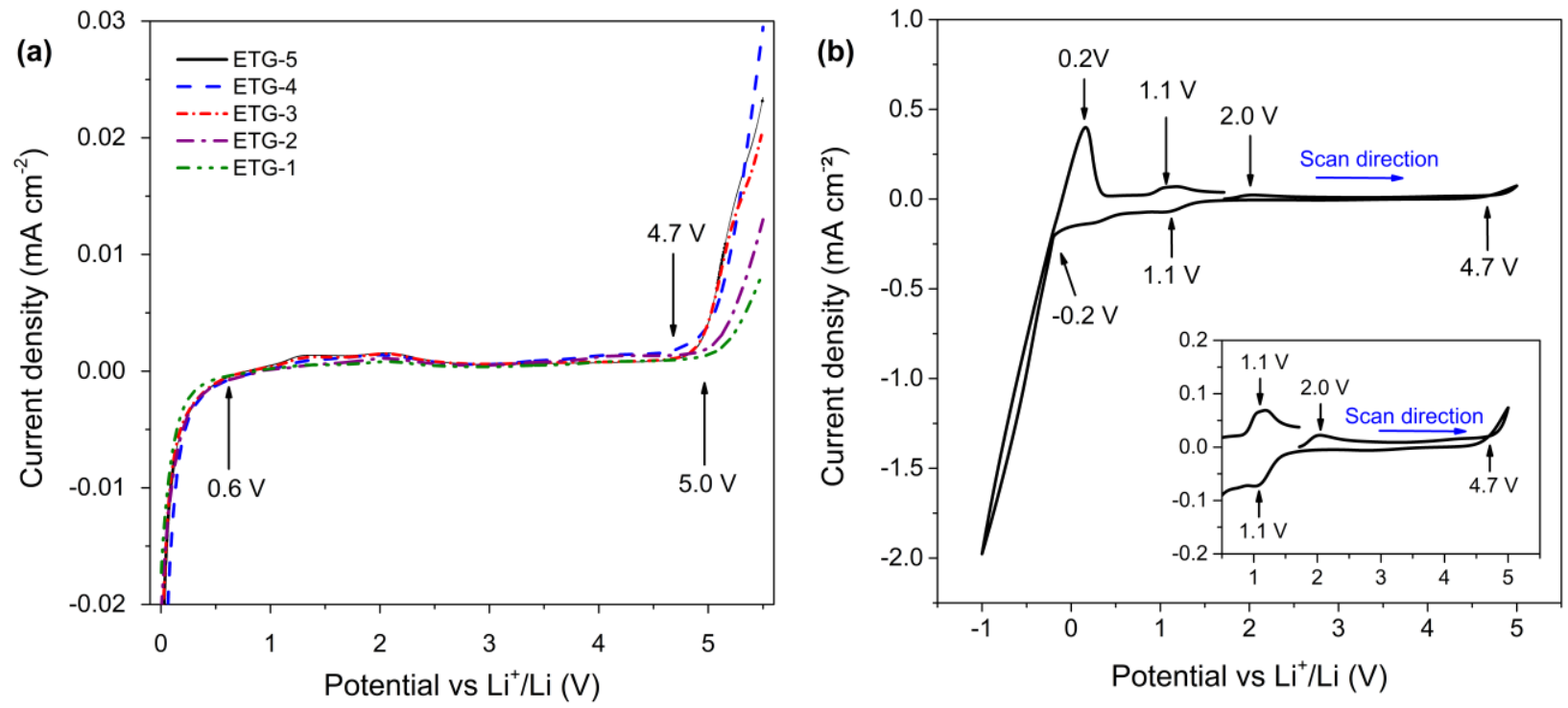

Figure 5: (a) LSV curves of all ETGs and (b) CV curves of ETG-5 in a cell with stainless steel as the working electrode and lithium as the counter electrode. Inset shows the zoom-in view of the $\mathrm{CV}$ curve between 0.5 and ${ }_{5} \mathrm{~V}(\mathrm{vs} \mathrm{Li} / \mathrm{Li})$.

The EIS analysis of ETGs, however, shows promising results for ionic conductivity, i.e. as high as $1.46 \mathrm{mS} \mathrm{cm}^{-1}$ at room temperature in ETG-5 (Table 3). For comparison, the DES itself displays an ionic conductivity around $1.5 \mathrm{mS} \mathrm{cm}^{-}$ ${ }^{1}$ at room temperature as found by Boisset et al. ${ }^{26}$ The ionic conductivity of ETGs as a function of temperature is plotted in Figure 4 between $-14{ }^{\circ} \mathrm{C}$ and $55^{\circ} \mathrm{C}$. In this plot, a discontinuity is recognized around $10{ }^{\circ} \mathrm{C}$, which suggests that conduction energetics for charge carriers are different at temperatures below and above $10{ }^{\circ} \mathrm{C}$. This energetics change might be attributed to the appearance of the LiTFSI solid phases below $10^{\circ} \mathrm{C}$, which was suggested by means of DSC analysis, i.e. a broad but minor endothermic melting signal is found around $-3.64{ }^{\circ} \mathrm{C}$ for the reference DES (Figure 3 b). A similar phenomenon has been reported for other quasi solid-state electrolytes. $5,29,44$ The activation energies for ionic conduction in ETGs were further determined to be $0.56 \pm 0.08 \mathrm{eV}$ and $0.9 \pm 0.1 \mathrm{eV}$ for temperatures higher and lower than $10{ }^{\circ} \mathrm{C}$, respectively. The linear sweep voltammograms (Figure $5 \mathrm{~b}$ ) of ETGs at room temperature are devoid of any significant current peak between 1.1 and 4.8 $\mathrm{V}\left(\mathrm{vs} \mathrm{Li}^{+} / \mathrm{Li}\right)$.The oxidation of the electrolyte starts beyond $4.8 \mathrm{~V}$ similar to observation of Boisset et al for DES. ${ }^{27}$ This oxidation threshold is lower than that reported for Ionogels based on ionic liquids with LiTFSI salt, i.e., 5 to $5.2 \mathrm{~V}$ (vs $\mathrm{Li}^{+} / \mathrm{Li}$ ). $9,10,14$ Hence, we speculate that NMAC is the main culprit for the lower anodic stability in ETGs. Nonetheless, the anodic stability of ETGs is good enough for the state-of-the-art positive electrodes in lithium-ion batteries, e.g., lithium cobalt oxide (LCO), lithium iron phosphate (LFP), lithium nickel manganese cobalt oxide (NMC), lithium nickel aluminium oxide (NCA), lithium manganese oxide (LMO). There are, however, good prospects for application of ETGs in high-voltage cathodes, providing the substitution of NMAC with a more stable candidate, perhaps 2-oxazolidinone.

Two small current peaks (Figure $5 \mathrm{~b}$ ) are observed around 1.1 and $2.2 \mathrm{~V}$ (vs. $\left.\mathrm{Li}^{+} / \mathrm{Li}\right)$. At this moment, we can only surmise that the water traces present in the ETGs $(<200 \mathrm{ppm})$ and silicon groups are responsible for the observed electrochemical activity at the latter and former potentials, respectively.14, 27 Cyclic voltammograms of the DES (figure $\mathrm{S}_{4}$ ), in absence of silica, reveal the same features but are devoid of any signal around $1.1 \mathrm{~V}$, confirming its origin to be the silicon groups. The cyclic voltammograms of the ETGs (Figure 5a) support the results of LSV tests. The onset of cathodic current at $-0.2 \mathrm{~V}$ and the anodic current peak at $0.2 \mathrm{~V}$ correspond to the plating and stripping of lithium at the stainless-steel working electrode, respectively.

The thermal and electrochemical stability of ETGs are barely sensitive to DES load, while higher DES content in the formulation of ETGs is greatly in favor of fast ionic conduction (Figure 4). We expect as well a better wetting of the electrodes when higher DES loads are employed, which in turn lowers the resistance at the electrolyte/electrodes interface. Hence, the performance of ETG-5 was further investigated in a coin cell with lithium-iron-phosphate (LFP) and Li as the cathode and anode, respectively.

The specific capacity of Li/ETG/LPF cell increases from 110 to $114 \mathrm{mAh} \mathrm{g}^{-1}$ after the first 10 cycles at $\mathrm{C} / 20$ (Figure $6 \mathrm{~b}$ ). Smaller discharge capacities are further obtained upon increase in the C-rate, i.e., $70 \mathrm{mAh} \mathrm{g}^{-1}$ at $1 \mathrm{C}$. We notice further rise in capacity (122 $\left.\mathrm{mAh} \mathrm{g}^{-1}\right)$ of the cells on completion of the rate-capability test and when the current is restored to the starting C-rate, i.e., C/20. Our primary investigations suggest that the presence of such an activation period is the result of a rather sluggish wetting of the LFP with ETG 

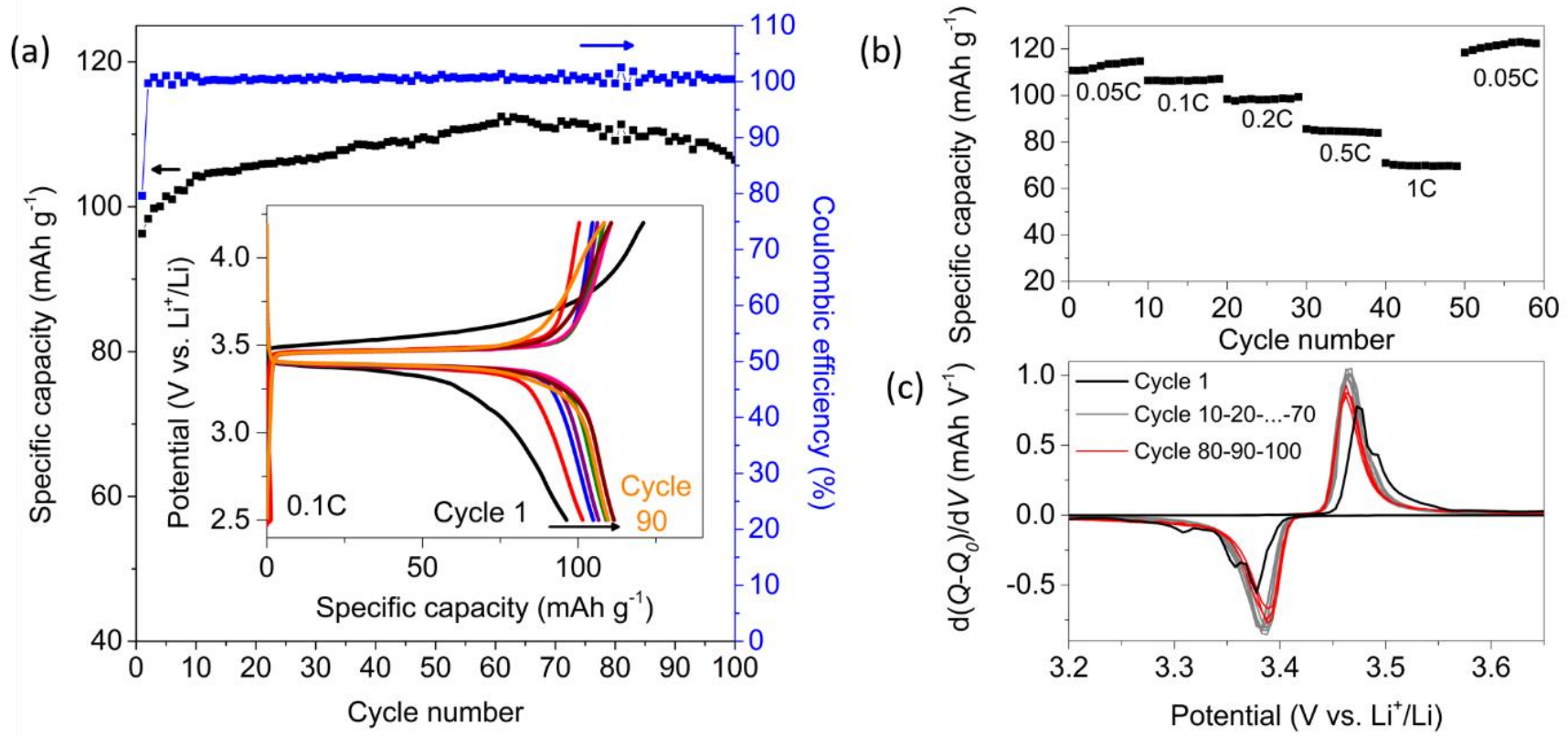

Figure 6: (a) Cycle performance and coulombic efficiency of a $\mathrm{Li} / \mathrm{LiFePO}_{4}$ cell with $\mathrm{ETG}-5$ as the electrolyte (inset: chargedischarge curves for cycles 1, 5, 15, 30, 45, 6o, 75, 90) (b) rate capability test of the aforementioned cell (c) Differential capacity analysis of the aforementioned cell $(\mathrm{dV}=10 \mathrm{mV})$.

electrolyte. This speculation is supported by the high viscosity of reference DES $\left(162.2 \mathrm{cp}\right.$ at shear rate of $\left.10 \mathrm{~s}^{-1}\right)$ and similar observations reported in the literature for ionic-liquids. ${ }^{10,11,29}$ The performance of the ETG based cells is very similar to the cells we assembled with conventional liquid electrolyte, i.e. $1 \mathrm{M} \mathrm{LiPF}_{6}$ in 50/50 vol\% EC/DEC. For instance, the discrepancy between the discharge capacity of the ETG-based and conventional cell is about $10 \%$ independent of $\mathrm{C}$-rate, respectively (see figure $\mathrm{S}_{5}$ ).

The long-term cycling of the cell was investigated via continuous charge-discharge at a constant rate of $\mathrm{C} / 10$ over 100 cycles. Similar to the cells in the rate-capability test, the capacity increases in the first 10 cycles from 96 to 104 $\mathrm{mAh} \mathrm{g}{ }^{-1}$. A capacity of $112 \mathrm{mAh} \mathrm{g}^{-1}$ is reached after cycle 60 . The cell performance remains very stable (Figure 6a) and with a coulombic efficiency well above $99.4 \%$. This result was further highlighted in the differential capacity plots (Figure 6c). Here, the position of insertion/de-insertion peaks after the first few cycles $(3.37 / 3.47 \mathrm{~V})$ stabilize at 3.38/3.46 V and remain unchanged for the rest of cycles. Additional peaks are observed in the first cycles but disappear upon further cycling. These peaks might be ascribed to the impurities (e.g. residual water) and will be further investigations in the future studies.

\section{CONCLUSIONS}

ETGs were introduced as a new class of solid composite electrolytes and prepared easily via a non-aqueous sol-gel route. The deep-eutectic solvent (i.e., NMAC and LiTFSI) in the formulation of ETGs is well compatible with the acidic conditions of the sol-gel process. These solid com- posite electrolytes demonstrate an acceptable thermal stability $\left(130^{\circ} \mathrm{C}\right)$ together with a broad electrochemical stability window (1.1-4.8 V) and high ionic conductivity at room temperature $\left(1.4 \mathrm{mS} \mathrm{cm}^{-1}\right)$. The Li/LFP half cells assembled with ETGs, deliver stable and reversible specific capacity of $105 \mathrm{mAhg}^{-1}$ at $0.1 \mathrm{C}$ and $17^{\circ} \mathrm{C}$ for over 60 cycles. Our findings suggest a good prospect for application of ETGs in LIBs and LMBs, hence opening up new horizons towards safer, cheaper and more performant batteries. The insights gained in this research pave the road for further improvements to the system, and will trigger more investigations and development of this new class of electrolytes.

\section{ASSOCIATED CONTENT}

Supporting Information. Nitrogen physisorption (isotherms, pore size distributuion); TG-MS of the eutectogel; CV of the DES; and rate capability of liquid electrolyte based LFP cell. This material is available free of charge via the Internet at http://pubs.acs.org.

\section{AUTHOR INFORMATION}

\section{Corresponding Author}

*E-mail: bjorn.joos@uhasselt.be

\section{ACKNOWLEDGMENT}

B. Joos is a PhD research fellow of the Research Foundation Flanders (FWO Vlaanderen). This project receives the support of the European Union, the European Regional Development Fund ERDF [project 936], Flanders Innovation \& Entrepreneurship and the Province of Limburg. The authors would like to thank Gilles Bonneux for the SEM measurements, Fulya Ulu for the TEM measurements, 
Dries De Sloovere for the FT-IR measurements, and prof. dr. Robert Carleer and the TANC group members for the many discussions, DSC, ICP-AES measurements and Kjeldahl titrations. Furthermore, the authors would like to thank prof. dr. Vera Meynen, Karen Leyssens and Romy Huysmans for performing and interpreting the nitrogen physisorption measurements.

\section{REFERENCES}

1. Cao, C.; Li, Z.; Wang, X.-L.; Zhao, X.; Han, W.-Q., Recent advances in inorganic solid electrolytes for lithium batteries. Frontiers in Energy Research 2014, 2, (25), 1-10.

2. Yoshimatsu, I.; Hirai, T.; Yamaki, J. i., Lithium electrode morphology during cycling in lithium cells. Journal of the Electrochemical Society 1988, 135, (10), 24222427.

3. Lu, Y.; Korf, K.; Kambe, Y.; Tu, Z.; Archer, L. A., Ionic-Liquid-Nanoparticle Hybrid Electrolytes: Applications in Lithium Metal Batteries. Angewandte Chemie International Edition 2014, 53, (2), 488-492.

4. Li, H.; Yin, H.; Wang, K.; Cheng, S.; Jiang, K.; Sadoway, D. R., Liquid Metal Electrodes for Energy Storage Batteries. Advanced Energy Materials 2016, 6, (14), 1600483-n/a.

5. Néouze, M.-A.; Le Bideau, J.; Gaveau, P.; Bellayer, S.; Vioux, A., Ionogels, New Materials Arising from the Confinement of Ionic Liquids within Silica-Derived Networks. Chemistry of Materials 2006, 18, (17), 3931-3936.

6. Sirisopanaporn, C.; Fernicola, A.; Scrosati, B., New, ionic liquid-based membranes for lithium battery application. Journal of Power Sources 2009, 186, (2), 490-495.

7. Néouze, M.-A.; Le Bideau, J.; Vioux, A., Versatile heat resistant solid electrolytes with performances of liquid electrolytes. Progress in Solid State Chemistry 2005, 33, (2), 217-222.

8. Lunstroot, K.; Driesen, K.; Nockemann, P.; Görller-Walrand, C.; Binnemans, K.; Bellayer, S.; Le Bideau, J.; Vioux, A., Luminescent ionogels based on europiumdoped ionic liquids confined within silica-derived networks. Chemistry of materials 2006, 18, (24), 5711-5715.

9. Tan, G.; Wu, F.; Zhan, C.; Wang, J.; Mu, D.; Lu, J.; Amine, K., Solid-State Li-Ion Batteries Using Fast, Stable, Glassy Nanocomposite Electrolytes for Good Safety and Long Cycle-Life. Nano Lett 2016, 16, (3), 196o-8.

10. Li, X.; Li, S.; Zhang, Z.; Huang, J.; Yang, L.; Hirano, S.-i., High-performance polymeric ionic liquid-silica hybrid ionogel electrolytes for lithium metal batteries. Journal of Materials Chemistry A 2016, 4, (36), 13822-13829.

11. Li, X.; Zhang, Z.; Yin, K.; Yang, L.; Tachibana, K.; Hirano, S.-i., Mesoporous silica/ionic liquid quasi-solidstate electrolytes and their application in lithium metal batteries. Journal of Power Sources 2015, 278, 128-132.
12. Echelmeyer, T.; Meyer, H. W.; van Wüllen, L., Novel Ternary Composite Electrolytes: Li Ion Conducting Ionic Liquids in Silica Glass. Chemistry of Materials 2009, 21, (11), 2280-2285.

13. Wu, F.; Tan, G.; Chen, R.; Li, L.; Xiang, J.; Zheng, Y., Novel Solid-State $\mathrm{Li} / \mathrm{LiFePO}_{4}$ Battery Configuration with a Ternary Nanocomposite Electrolyte for Practical Applications. Advanced Materials 2011, 23, (43), 5081-5085.

14. Wu, F.; Chen, N.; Chen, R.; Wang, L.; Li, L., Organically modified silica-supported ionogels electrolyte for high temperature lithium-ion batteries. Nano Energy 2017, 31, 9-18.

15. Le Bideau, J.; Ducros, J.-B.; Soudan, P.; Guyomard, D., Solid-State Electrode Materials with Ionic-Liquid Properties for Energy Storage: the Lithium Solid-State IonicLiquid Concept. Advanced Functional Materials 2011, 21, (21), 4073-4078.

16. Guyomard-Lack, A.; Abusleme, J.; Soudan, P.; Lestriez, B.; Guyomard, D.; Bideau, J. L., Hybrid Silica-Polymer Ionogel Solid Electrolyte with Tunable Properties. Advanced Energy Materials 2014, 4, (8), 1301570-n/a.

17. Torimoto, T.; Tsuda, T.; Okazaki, K.-i.; Kuwabata, S., New Frontiers in Materials Science Opened by Ionic Liquids. Advanced Materials 2010, 22, (11), 1196-1221.

18. Abbott, A. P.; Boothby, D.; Capper, G.; Davies, D. L.; Rasheed, R. K., Deep Eutectic Solvents Formed between Choline Chloride and Carboxylic acids: versatile Alternatives to Ionic liquids, Journal of the American Chemical Society, 2004, 129, (29), 9142-9147.

19. Abbott, A. P.; Capper, G.; Davies, D. L.; Munro, H. L.; Rasheed, R. K.; Tambyrajah, V., Preparation of novel, moisture-stable, Lewis-acidic ionic liquids containing quaternary ammonium salts with functional side chains. Chemical Communications 2001, (19), 2010-2011.

20 Abbott, A. P.; Capper, G.; Davies, D. L.; Rasheed, R. K.; Tambyrajah, V., Novel solvent properties of choline chloride/urea mixtures. Chemical communications 2013, (1), 70-71.

21. Smith, E. L.; Abbott, A. P.; Ryder, K. S., Deep Eutectic Solvents (DESs) and Their Applications. Chemical Reviews 2014, 114, (21), 11060-11082.

22. Pena-Pereira, F.; Namieśnik, J., Ionic Liquids and Deep Eutectic Mixtures: Sustainable Solvents for Extraction Processes. ChemSusChem 2014, 7, (7), 1784-18oo.

23. Zhang, Q.; De Oliveira Vigier, K.; Royer, S.; Jerome, F., Deep eutectic solvents: syntheses, properties and applications. Chemical Society Reviews 2012, 41, (21), 71087146.

24. Francisco, M.; van den Bruinhorst, A.; Kroon, M. C., Low-Transition-Temperature Mixtures (LTTMs): A New Generation of Designer Solvents. Angewandte Chemie International Edition 2013, 52, (11), 3074-3085. 
25. Marsh, K.; Boxall, J.; Lichtenthaler, R., Room temperature ionic liquids and their mixtures-a review. Fluid Phase Equilibria 2004, 219, (1), 93-98.

26. Boisset, A.; Jacquemin, J.; Anouti, M., Physical properties of a new Deep Eutectic Solvent based on lithium bis[(trifluoromethyl)sulfonyl]imide and N-methylacetamide as superionic suitable electrolyte for lithium ion batteries and electric double layer capacitors. Electrochimica Acta 2013, 102, 120-126.

27. Boisset, A.; Menne, S.; Jacquemin, J.; Balducci, A.; Anouti, M., Deep eutectic solvents based on N-methylacetamide and a lithium salt as suitable electrolytes for lithium-ion batteries. Physical Chemistry Chemical Physics 2013, 15, (46), 20054-20063.

28. Zaidi, W.; Boisset, A.; Jacquemin, J.; Timperman, L.; Anouti, M., Deep Eutectic Solvents Based on NMethylacetamide and a Lithium Salt as Electrolytes at Elevated Temperature for Activated Carbon-Based Supercapacitors. The Journal of Physical Chemistry C 2014, 118, (8), 4033-4042.

29. Wu, F.; Tan, G.; Chen, R.; Li, L.; Xiang, J.; Zheng, Y., Novel Solid-State $\mathrm{Li} / \mathrm{LiFePO}_{4}$ Battery Configuration with a Ternary Nanocomposite Electrolyte for Practical Applications. Advanced Materials 2011, 23, (43), 5081-5085.

3o. Kubelka, J.; Keiderling, T. A., Ab Initio Calculation of Amide Carbonyl Stretch Vibrational Frequencies in Solution with Modified Basis Sets. 1. N-Methyl Acetamide. The Journal of Physical Chemistry A 2001, 105, (48), 1092210928.

31. Wu, Y.; Xu, Y.; Wang, D.; Zhao, Y.; Weng, S.; Xu, D.; Wu, J., FT-IR spectroscopic investigation on the interaction between nylon 66 and lithium salts. Journal of Applied Polymer Science 2004, 91, (5), 2869-2875.

32. Hernandez, M.; Servant, L.; Grondin, J.; Lassègues, J.-C., Spectroscopic characterization of metal chloride/polyamide complexes. Ionics 1995, 1, (5), 454-468.

33. Swann, G. E.; Patwardhan, S., Application of Fourier Transform Infrared Spectroscopy (FTIR) for assessing biogenic silica sample purity in geochemical analyses and palaeoenvironmental research. Climate of the Past 2011, 7, (1), 65-74
34. Musić, S.; Filipović-Vinceković, N.; Sekovanić, L., Precipitation of amorphous $\mathrm{SiO}_{2}$ particles and their properties. Brazilian journal of chemical engineering 2011, 28, (1), 89-94.

35. Lassègues, J.-C.; Grondin, J.; Aupetit, C.; Johansson, P., Spectroscopic Identification of the Lithium Ion Transporting Species in LiTFSI-Doped Ionic Liquids. The Journal of Physical Chemistry A 2009, 113, (1), 305-314.

36. Rey, I.; Johansson, P.; Lindgren, J.; Lassègues, J. C.; Grondin, J.; Servant, L., Spectroscopic and Theoretical Study of ( $\left.\mathrm{CF}_{3} \mathrm{SO}_{2}\right)_{2} \mathrm{~N}$ - (TFSI-) and ( $\left.\mathrm{CF}_{3} \mathrm{SO}_{2}\right)_{2} \mathrm{NH}$ (HTFSI). The Journal of Physical Chemistry A 1998, 102, (19), 32493258 .

37. Hu, Y.; Wang, Z.; Li, H.; Huang, X.; Chen, L., Spectroscopic and DFT studies to understand the liquid formation mechanism in the LiTFSI/acetamide complex system. Spectrochimica Acta Part A: Molecular and Biomolecular Spectroscopy 2005, 61, (9), 2009-2015.

38. Cai, X.; Hong, R.; Wang, L.; Wang, X.; Li, H.; Zheng, Y.; Wei, D., Synthesis of silica powders by pressured carbonation. Chemical Engineering Journal 2009, 151, (1), 380-386.

39. Karmakar, B.; De, G.; Ganguli, D., Dense silica microspheres from organic and inorganic acid hydrolysis of TEOS. Journal of non-crystalline solids 2000, 272, (2), 119126.

40. Kimura, K.; Hassoun, J.; Panero, S.; Scrosati, B.; Tominaga, Y., Electrochemical properties of a poly (ethylene carbonate)-LiTFSI electrolyte containing a pyrrolidinium-based ionic liquid. Ionics 2015, 21, (3), 895-900.

41. Sun, B.; Mindemark, J.; Edström, K.; Brandell, D., Polycarbonate-based solid polymer electrolytes for Li-ion batteries. Solid State Ionics 2014, 262, 738-742.

42. Nadherna, M.; Dominko, R.; Hanzel, D.; Reiter, J.; Gaberscek, M., Electrochemical behavior of $\mathrm{Li}_{2} \mathrm{FeSiO}_{4}$ with ionic liquids at elevated temperature. Journal of the Electrochemical Society 2009, 156, (7), A619-A626.

43. Zeitschrift für analytische Chemie. J. F. Bergmann: 1883.

44. MacFarlane, D. R.; Forsyth, M., Plastic crystal electrolyte materials: new perspectives on solid state ionics. Advanced materials 2001, 13, (12-13), 957-966. 


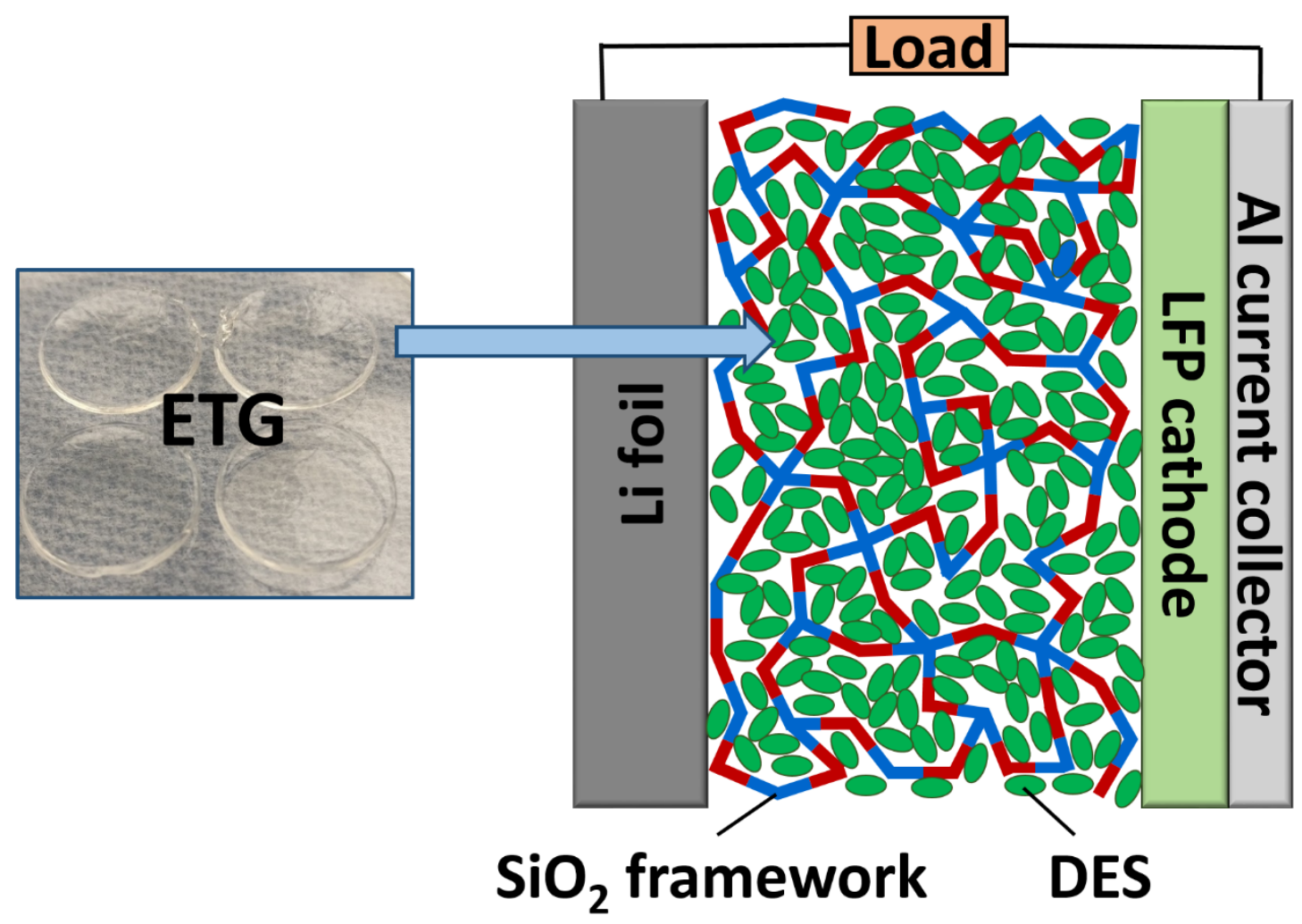

